\title{
Capitalismo consciente e governança corporativa: construção de conhecimento com base na literatura
}

\author{
Daniel Cargnin da Silva Mestrando em Administração. Universidade do Sul de Santa Catarina (UNISUL) - Brasil. \\ cargnindaniel@gmail.com \\ Ademar Dutra Doutor em Engenharia de Produção. Universidade do Sul de Santa Catarina (UNISUL) - Brasil. \\ ademar.dutra@unisul.br \\ Simone Sehnem Doutora em Administração e Turismo. Universidade do Sul de Santa Catarina (UNISUL) - Brasil. \\ simonesehnem_adm@yahoo.com.br \\ Graciella Martignago Doutora em Administração. Universidade do Sul de Santa Catarina (UNISUL) - Brasil. \\ graciellamartignago@gmail.com
}

\section{RESUMO}

O objetivo deste artigo é analisar as características básicas e avançadas das publicações internacionais relacionadas ao recorte do tema Capitalismo Consciente e Governança Corporativa, por meio do instrumento KnowledgeDevelopmentProcess - Constructivist (ProKnow-C). Foram identificadas as variáveis básicas do Portfólio Bibliográfico relacionadas a caracterização dos autores mais prolíficos, artigos com maior reconhecimento e relevância científica e periódicos que mais disseminam tais publicações, e analisadas as variáveis avançadas que evidenciam o atendimento dos princípios do capitalismo consciente, fundamentados no autorMackey e Sisodia (2014). Verificou-se que o autor de destaque foi Hoje Joe como periódico de destaque o Journalof Business Ethics. Por meioda análise das variáveis avançadas, observou-se que nenhum dos artigos do portfólio bibliográfico trata especificamente da teoria do Capitalismo Consciente, no entanto a maioria dos artigos do portfólio possui convergências com a teoria.

Palavras-Chave: Capitalismo Consciente. Governança Corporativa.Proknow-C.

\section{Conscious capitalism and corporate governance: construction of knowledge based on the literature}

\begin{abstract}
The objective of this article is to analyze the basic and advanced characteristics of the international publications related to the cutting of the theme Conscious Capitalism and Corporate Governance, through the tool Knowledge Development Process - Constructivist (ProKnow-C). The basic variables of the Bibliographic Portfolio related to the characterization of the most prolific authors, articles with greater recognition and scientific relevance, and periodicals that disseminate such publications more widely, and the advanced variables that evidence the principles of conscious capitalism based on the author Mackey and Sisodia (2014). It was found that the prominent author was Today Joe as featured journal of Journal of Business Ethics. Through the analysis of the advanced variables, it was observed that none of the articles in the bibliographic portfolio deals specifically with the theory of Conscious Capitalism, however most articles in the portfolio have convergence with theory.
\end{abstract}

Keywords: Conscious Capitalism. Corporate governance. Proknow-C. 


\title{
1 INTRODUÇÃO
}

A Responsabilidade Social Corporativa é um conceito que atraiu atenção e interesse mundial nos últimos anos, devido à globalização e do comércio internacional (JAMALI; SAFIEDDINE; RABBATH, 2008). De acordo com Ingley (2008) as organizações raramente podem se dar ao luxo de adotar a visão deque "a responsabilidade social dos negócios é aumentar seus lucros [...]" (FRIEDMAN, 1970, apud INGLEY, 2008, p. 18).

Apesar da proposta de somente maximizar os lucros dos acionistas de Friedman ainda ser muito presente nas organizações e, muitas vezes, ser obstáculo para as organizações que desejam se tornar mais sustentáveis (SNEIRSON, 2009), as organizações estão mais inclinadas a ampliar a base de sua avaliação de desempenho, considerando não somente lucros, mas impactos sociais, ambientais e econômicos de longo prazo e valor agregado (JAMALI; SAFIEDDINE; RABBATH, 2008). Esse movimento das empresas de preocuparem-se com o impacto ambiental e social pode ser denominado como Responsabilidade Social Corporativa, que se juntou aos esforços políticos para tornar as empresas mais sintonizadas com as necessidades públicas, ambientais e sociais, buscando a governança corporativa como um quadro para as organizações tratarem funcionários, consumidores e comunidades de forma semelhante aos acionistas (GILL, 2008).

Para a Responsabilidade Social Corporativa se tornar possível é fundamental que ela seja incorporada na Governança Corporativa. Houve uma discussão notável nas duas últimas décadas entre estudiosos e profissionais sobre o que constituem as melhores práticas de governança corporativa (JO; MARETNO; HARJOTO, 2011). As empresas que praticam a boa governança são esperadas pelo público para demonstrar uma boa cidadania corporativa, sendo responsável não só pelos acionistas e investidores, mas também por outras partes interessadas e pela comunidade em geral dentro da qual eles existem (INGLEY, 2008). Nesse sentido, Ingley (2008) afirma que a governança sustentável não é uma opção. É uma expectativa fundamental dos governos, dos mercados e de todas as partes da sociedade civil, para restaurar a confiança pública e criar confiança, as empresas devem comprometer-se à abertura, transparência e justiça.

Dentro deste contexto, há algumas pesquisas que visam analisar como fazer com que a Governança Corporativa incorpore valores e diretrizes sustentáveis, visando criação de valor a longo prazo e desenvolvimento sustentável para as organizações. A teoria do Capitalismo Consciente, criada por John Mackey, é uma proposta de resposta a esta questão.

Conforme Mackey e Sisodia (2014, p. 35)

\begin{abstract}
o capitalismo consciente é um paradigma em desenvolvimento para os negócios que simultaneamente cria vários tipos de valor e bem-estar para todas as partes interessadas: financeiro, intelectual, físico, ecológico, social, cultural, emocional, ético e até mesmo espiritual. [...] A prática do capitalismo consciente não se resume a ser virtuoso ou trabalhar para fazer o bem. Trata-se de uma maneira de pensar o negócio com mais consciência de seu propósito maior, de seus impactos sobre o mundo e de suas relações com os diversos públicos e stakeholders.
\end{abstract}

O Capitalismo Consciente possui quatro princípios (MACKEY; SISODIA, 2014): (1) propósito maior: razão de existência da empresa, que vai além de gerar lucro e criar valor para os investidores; (2) Integração de stakeholders (todas as entidades que impactam ou são impactadas pela organização): todos estão conectados e são interdependentes e o negócio deve otimizar a criação de valor para eles; (3) Liderança Consciente: líderes que busca soluções sinérgicas, rejeitando a visão de negócios orientadas para trade-offs, agregando valor para os stakeholders e agindo de acordo com o propósito maior da organização; e (4) Cultura e Gestão Conscientes: cultura que garante estabilidade à organização, assegurando que os valores e propósito sobreviverão ao longo do tempo e às mudanças de liderança. Compartilham de características como confiança, responsabilidade, transparência, integridade, lealdade, igualitarismo, justiça e crescimento pessoal. A gestão consciente utiliza uma abordagem compatível com esta cultura.

Nesse sentido, emerge a pergunta de pesquisa: quais as características das publicações internacionais acerca do tema capitalismo consciente e governança corporativa? Com base nesse contexto, tem-se como objetivo principal analisar as características básicas e avançadas das publicações internacionais relacionadas ao recorte do tema Capitalismo Consciente e Governança Corporativa, por meio do instrumento 
KnowledgeDevelopmentProcess - Constructivist (ProKnow-C). Como objetivos específicos destacam-se: (i) identificar as variáveis básicas do Portfólio Bibliográfico relacionadas à caracterização dos autores mais prolíficos, artigos com maior reconhecimento e relevância científica e periódicos que mais disseminam tais publicações; (ii) analisar as variáveis avançadas que evidenciam o atendimento dos princípios do capitalismo consciente, fundamentados nos autores Mackey e Sisodia (2014).

Esta pesquisa justifica-se pelo fato da sociedade estar cada vez mais exigindo que as empresas se desenvolvam de forma sustentável, sem comprometer as gerações futuras. As ações voltadas para a sustentabilidade aumentaram quase dez vezes nos últimos 20 anos e quase triplicaram desde 2006 (MARTIN; JOHNSON; FRENCH, 2011). Houve crescente aceitação do papel substancial e indispensável da sustentabilidade, o que leva as empresas a adotarem atitudes mais sustentáveis (WEl; EGRI; LIN, 2014).Além disso, a divulgação de informações por meio de relatórios de sustentabilidade tem se tornado uma aliada importante diante do mercado cada vez mais competitivo, visando ganho de legitimação e sustentabilidade da empresa (MACHADO; OTT, 2015). Buscas preliminares a este trabalho, demonstraram que há poucos materiais sobre o tema, visto que a teoria do Capitalismo Consciente é recente, e não há artigos publicados em língua portuguesa sobre o tema, conforme pesquisa efetuada pelo termo "Capitalismo Consciente" na base Spell e revistas de administração RAE e BAR e site do instituto Capitalismo Consciente no Brasil.

Esse trabalho está dividido em cinco seções, sendo a primeira correspondente à Introdução; a segunda seção aborda o quadro teórico sobre o tema com base nos artigos selecionados por meio do ProKnow- $C$; a terceira seção apresenta o enquadramento metodológico e os procedimentos realizados para coleta e seleção do portfólio bibliográfico; a quarta seção aborda a análise bibliométrica dos artigos (variáveis básicas e avançadas) e a quinta seção as considerações finais desse estudo.

\section{REFERENCIAL TEÓRICO}

Esta seção do artigo aborda aspectos teóricos alusivos à responsabilidade social corporativa e governança, variáveis básicas e avançadas.

\subsection{Responsabilidade social corporativa e governança corporativa}

A sustentabilidade é um tema controverso porque significa coisas diferentes para pessoas diferentes (ARAS; CROWTHER, 2008). Serão apresentados alguns conceitos presentes na literatura, para um melhor entendimento do termo, em especial relacionado à Responsabilidade Social Corporativa. Sustentabilidade pode ser entendida como a capacidade de atendimento às necessidades do presente sem comprometer o atendimento das necessidades das gerações futuras (SNEIRSON, 2009). Em outras palavras, a sociedade não deve utilizar mais recursos do que pode ser regenerado (ARAS; CROWTHER, 2008).

No contexto organizacional a sustentabilidade pode ser caracterizada como uma visão de longo prazo, que se refere a um conceito de responsabilidade corporativa global, incluindo aspectos legais, econômicos, sociais e ambientais Esta abordagem implica o equilíbrio de interesses de todos aqueles que contribuem para o sucesso da empresa atual e futura, através da criação de valor sustentável que satisfaça os acionistas e outras partes interessadas no longo prazo Em outras palavras, a sustentabilidade corporativa significa que as empresas devem considerar o futuro e o presente, em suas decisões e ações, com o objetivo de usar seus recursos para criar valor a longo prazo. (SALVIONI; GENNARI; BOSETTI, 2016). Ainda dentro do contexto organizacional, existe o termo Responsabilidade Social Corporativa, que pode ser entendida como uma forma de "alcançar o sucesso comercial de forma que respeitem os valores éticos, as pessoas, as comunidades e o ambiente natural" (SCHACTER, 2005 apud INGLEY 2008, p. 19, tradução nossa).

Este termo ganhou força e atraiu atenção e interesse mundial nos últimos anos, devido à globalização e do comércio internacional, que se refletiram em uma maior complexidade empresarial e novas demandas de maior transparência e cidadania corporativa. Embora a maximização do valor para o acionista ainda seja um objetivo importante para as corporações em todo o mundo, o aumento do ativismo social e o surgimento 
de novas expectativas realmente fizeram com que outros aspectos do desempenho corporativo sejam examinados juntamente com os resultados financeiros (JAMALI; SAFIEDDINE; RABBATH, 2008).

Nesse sentido, Ingley (2008), afirma que esta nova forma de avaliar os resultados das organizações vai além da responsabilidade pelo impacto das atividades no ambiente social e físico. Impacta também na geração de resultados sociais aprimorados em paralelo com o melhor desempenho do negócio. Além disso, houve uma evolução do conceito ao longo do tempo, para a compreensão atual de que o desenvolvimento sustentável é um processo que integra objetivos econômicos, ambientais e sociais (VAN ZEIJL-ROZEMA et al., 2008). Em vez de considerar a Responsabilidade Social Corporativa como uma nova exigência de conformidade, as empresas estão começando a reconhecer o conceito como apresentando um novo modelo de negócios e uma oportunidade para criar formas inovadoras de vantagem competitiva (INGLEY 2008).

A Responsabilidade Social Corporativa pode ser estudada como abrangendo duas dimensões: interna e externa. No nível interno, as empresas revisam as suas prioridades internas e dão atenção a sua responsabilidade para as partes interessadas internas, abordando questões como segurança e condições de trabalho, direitos humanos, considerações de equidade, igualdade de oportunidades, saúde e direitos trabalhistas. A dimensão externa diz respeito às corporações assumirem seus deveres como cidadãos e concederem a devida atenção às suas partes externas econômicas, sociais e ao ambiente natural (JAMALI; SAFIEDDINE; RABBATH, 2008).

Dentro dessa perspectiva de estudo da Responsabilidade Social Corporativa, surgem questões de como a empresa pode se tornar mais responsável, de como transformar os negócios em socialmente responsáveis. Para responder essas questões, é necessário abordar a Governança Corporativa, que pode ser entendida como um conjunto de regras, envolvimento das partes interessadas e processos para realizar um objetivo comum (VAN ZEIJL-ROZEMA et al., 2008). De acordo com Gill (2008) a governança corporativa especifica regras de tomada de decisão de negócios que se aplicam aos mecanismos internos das empresas. Serve para moldar as relações entre conselhos de administração, acionistas e gerentes, bem como para resolver conflitos. Em outras palavras, a Governança Corporativa é "o sistema pelo qual as empresas são direcionadas e controladas" (CADBURY, 2000 apud JAMALI; SAFIEDDINE; RABBATH, 2008, p. 444).

De acordo com Salvioni, Gennari, Bosetti (2016) a governança corporativa é uma combinação de estruturas e processos. Enquanto as estruturas se referem a todos os órgãos responsáveis pela direção e controle da empresa, os processos consistem nas atividades desenvolvidas para satisfazer as expectativas das partes interessadas. A Governança Corporativa também pode ser considerada como um ambiente de confiança, ética, valores morais e confiança - como um esforço sinérgico de todas as partes interessadas (ARAS; CROWTHER, 2008). A Governança Corporativa também está intimamente preocupada com a honestidade e a transparência, que são cada vez mais esperadas pelo público tanto nas relações corporativas quanto na divulgação de resultados. Outros elementos da Governança Corporativa incluem liderança corporativa e configuração de estratégia. Esses aspectos envolvem a definição de papéis e responsabilidades, orientando o gerenciamento para uma visão de longo prazo do desempenho corporativo (JAMALI; SAFIEDDINE; RABBATH, 2008).

A governança corporativa ganhou importância nos últimos anos (ARAS; CROWTHER, 2008). Para sobreviver a longo prazo em um ambiente volátil e incerto, as organizações contemporâneas devem satisfazer uma variedade de partes interessadas (stakeholders), que são capazes de infligir danos inaceitáveis sobre a viabilidade da organização se seus interesses não forem cumpridos (GARVARE; JOHANSSON, 2010). A crescente conscientização sobre a sustentabilidade induziu a difusão de uma nova abordagem ao lidar com as partes interessadas, como fonte de vantagem competitiva (SALVIONI; GENNARI; BOSETTI, 2016).

Para atender os interesses das partes interessadas, é necessário que as empresas incorporem a Responsabilidade Social Corporativa em sua Governança. Conforme Salvioni, Gennari, Bosetti (2016), no mundo de hoje, a abordagem sustentável da governança corporativa pode ser uma fonte de vantagem competitiva e um fator de sucesso a longo prazo. As empresas que entendem as questões ambientais, sociais e de governança como sendo centrais e as gerenciam de forma adequada, efetivamente criam valor (INGLEY 2008). Além disso, a literatura sobre Responsabilidade Social Corporativa inspirou críticas às razões econômicas por trás do centralismo dos acionistas. As abordagens orientadas para o bem-estar social para a 
legislação e a política societária propuseram que a eficiência das empresas não deveria ter somente como objetivo aumentar os preços das ações, mas também incorporar as questões ambientais e sociais (GILL, 2008).

A governança corporativa se torna cada vez mais conduzida por normas éticas e a necessidade de responsabilidade e a responsabilidade social corporativa se adapta às práticas comerciais prevalecentes (GILL, 2008). A governança sustentável exige que a organização considere as expectativas econômicas, sociais e ambientais de forma integrada, independentemente da estrutura de propriedade e das regras formais aplicáveis à empresa. Consequentemente, a adoção de uma abordagem de sustentabilidade modifica a direção da organização para a busca do desempenho econômico no longo e não curto prazo. (SALVIONI; GENNARI; BOSETTI, 2016). Desta forma, pode-se considerar que a governança é vista como um meio para orientar o processo de desenvolvimento sustentável (VAN ZEIJL-ROZEMA et al., 2008).

Por fim, o desenvolvimento sustentável não pode ser alcançado sem governança por sua natureza: promover objetivos comuns por ação coletiva (VAN ZEIJL-ROZEMA et al., 2008). Uma empresa sustentável só existirá ao reconhecer questões ambientais e sociais e incorporá-las ao seu planejamento estratégico (ARAS; CROWTHER, 2008).

\subsection{Variáveis básicas e avançadas}

Serão analisadas como variáveis básicas do portfólio bibliográfico e suas referências os autores, periódicos e artigos de destaque. O método de seleção dos artigos será detalhado na seção 3.2.

Para elaboração das variáveis avançadas, foi utilizado o livro Capitalismo Consciente: Como Libertar o Espírito Heroico dos Negócios, dos autores Mackey e Sisodia (2014). Optou-se pela utilização do livro por não ter sido localizado nenhum artigo que descrevesse de forma detalhada os princípios do Capitalismo Consciente, além de ter sido verificado que a versão original do livro (em inglês) possui relevância científica (278 citações conforme Google Scholar).

\section{METODOLOGIA DA PESQUISA}

Esta seção descreve o percurso metodológico percorrido para elaborar o estudo.

\subsection{Enquadramento metodológico}

O presente estudo visa realizar uma análise das características básicas e avançadas das publicações internacionais relacionadas ao recorte do tema Capitalismo Consciente e Governança Corporativa, por meio do instrumento KnowledgeDevelopmentProcess - Constructivist (ProKnow-C).Os objetivos específicos são identificar as variáveis básicas do Portfólio Bibliográfico relacionadas à caracterização dos autores mais prolíficos, artigos com maior reconhecimento e relevância científica e periódicos que mais disseminam tais publicações e analisar as variáveis avançadas que evidenciam o atendimento dos princípios do capitalismo consciente, fundamentados em Mackey e Sisodia (2014).

Dessa forma, caracteriza-se como uma abordagem qualitativa, que visa descrever, compreender determinados fenômenos e não os quantificar (COOPER; SCHINDLER, 2011).

O estudo caracteriza-se como exploratório-descritivo (RICHARDSON, 2012): exploratório por proporcionar aos pesquisadores reflexão e conhecimento sobre o assunto e descritivo por descrever as características do portfólio bibliográfico e suas referências. Foram utilizados dados secundários (RICHARDSON, 2012), oriundos de artigos do Portfólio Bibliográfico selecionado por meio de consulta às bases de dados detalhado a seguir. 


\subsection{Knowledge development process - constructivist (Proknow-c)}

Para seleção do portfólio bibliográfico, foi utilizado o instrumento KnowledgeDevelopmentProcess Constructivist (ProKnow-C), elaborado pelo professor pesquisador Leonardo Esslin, da Universidade Federal de Santa Catarina. O objetivo do Proknow-C "é construir conhecimento para o pesquisador que operacionaliza, a partir de seus interesses e delimitações, segundo uma visão construtivista" (VALMORBIDA; ESSLIN, 2015, p. 6). O Proknow-Ctem a finalidade de identificar um portfólio bibliográfico e as características dos estudos do tema escolhido, além de proceder uma análise crítica do portfólio, possibilitando a identificação de lacunas na literatura que permitam a formulação de problemas de pesquisa (VALMORBIDA; ESSLIN, 2015). A Figura 1 demonstra as etapas do Proknow-C.

Figura 1 -Macro etapas do Proknow-C

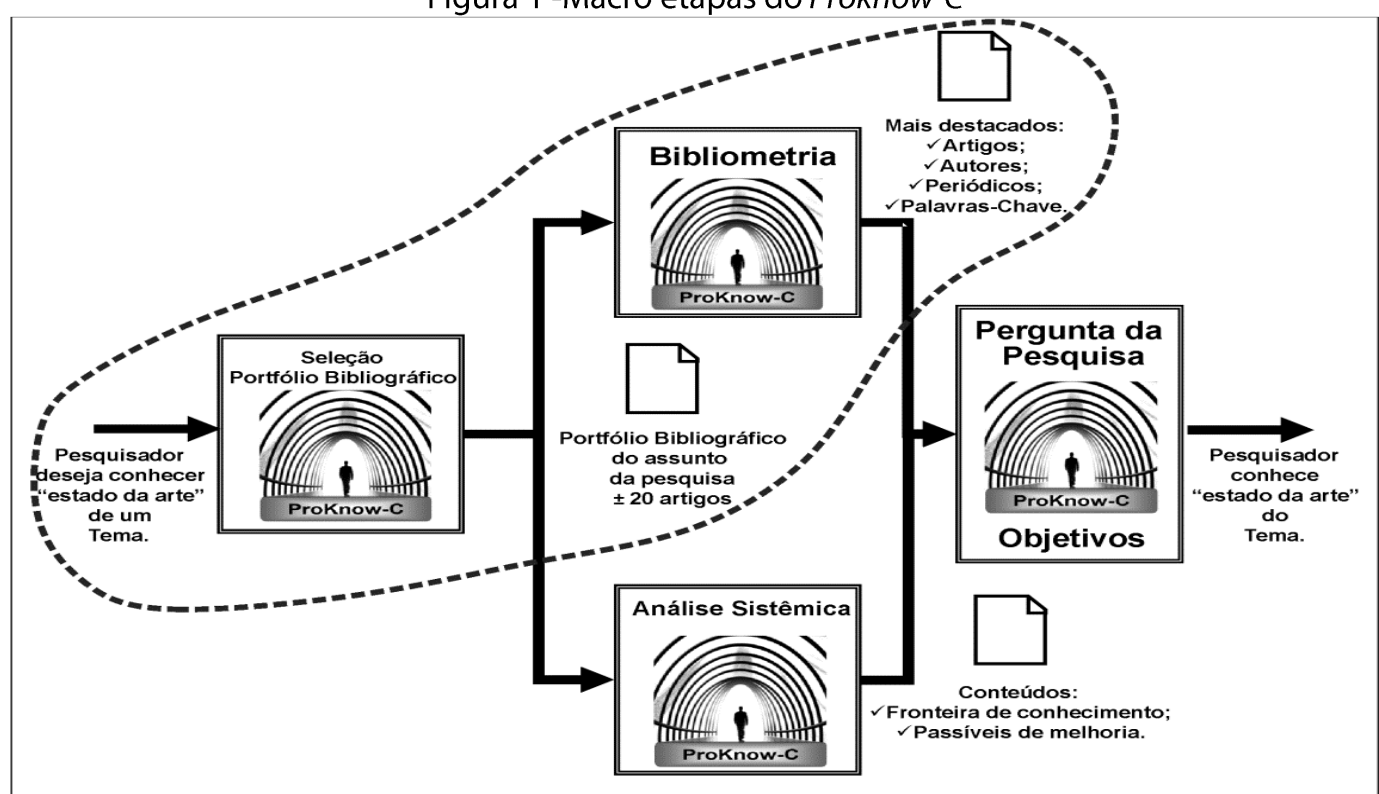

Fonte: Ensslin et al. (2010)

Nesse trabalho foram operacionalizadas as etapas (i) e (ii) conforme demonstrado na figura (seleção do Portfólio bibliográfico e bibliometria) detalhadas a seguir. As demais etapas (análise sistêmica e elaboração de pergunta e objetivos de pesquisa) não foram objeto desse trabalho. Estas etapas poderão ser seguidas para a elaboração de trabalhos futuros sobre o tema.

Foram definidos dois eixos de pesquisa e posteriormente palavras-chave para cada eixo. Conforme o objetivo do estudo, foram escolhidos os eixos Capitalismo Consciente (ConsciousCapitalism) como primeiro eixo e Governança Corporativa (Corporate Governance) como segundo eixo. Como palavras-chave do primeiro eixo foram escolhidas ConsciousCapitalism, Sustainability, SustainableLeadership, ConsciousLeadership, SustainableDevelopment e do segundo eixo Corporate Governance, Sustainable Governance, Stakeholder Management, Conscious Culture, Conscious Management, Transparency.

Após a definição das palavras-chave, foram criados comandos para realização da busca dos artigos nas bases de dados. Foram efetuadas buscas nas bases de dados EBSCO, Proquest, Scopus, Emerald, Wiley, WEB os Science, SAGE e Science Direct, utilizando o comando de busca conforme quadro 1. A pesquisa foi realizada nos dias 01 e 02 de abril de 2017, considerando somente artigos científicos publicados entre 2007 e 2017. 
Quadro 1 - Resultados da busca de artigos nas bases de dados

\begin{tabular}{|c|c|c|}
\hline Comando de Busca & Base de dados & $\begin{array}{c}\text { Quantidade de } \\
\text { artigos }\end{array}$ \\
\hline \multirow{8}{*}{$\begin{array}{l}\text { (“Conscious Capitalism" OR "Sustainability" OR } \\
\text { "Sustainable Leadership" OR "Conscious Leadership" } \\
\text { OR "Sustainable Development") AND } \\
\text { ("Corporate Governance" OR “Sustainable Governance" } \\
\text { OR "Stakeholder Management" OR "Conscious Culture" } \\
\text { OR “Conscious Management" OR “Transparency") }\end{array}$} & Scopus & 1080 \\
\hline & Web o Science & 777 \\
\hline & Wiley & 651 \\
\hline & EBSCO & 178 \\
\hline & Proquest & 78 \\
\hline & Emerald & 3 \\
\hline & Science Direct & 1 \\
\hline & SAGE & 0 \\
\hline
\end{tabular}

Fonte: Elaborado pelos autores (2017).

Verifica-se que as bases Scopus, Web of Science e Wiley foram as que mais possuíamartigos conforme comando de busca efetuado, correspondendo a $90 \%$ do total. Destaca-se ainda a base Scopus, onde foram localizados 39\% do total de artigos.As bases Emerald, Science Direct e SAGE foram as que menos apresentaram resultados (menos de $1 \%$ do total).

Após a realização da pesquisa nas bases de dados, obteve-se um Banco de Artigos Brutos com 2768 artigos. Para verificação da aderência das palavras-chave ao tema estudado, foram selecionados 3 artigos do Portfólio de Artigos Brutos e verificaram-se as palavras-chave desses artigos em comparação com as constantes no comando de busca do quadro 1, conforme demonstrado no quadro 2. As palavras em destaque demonstram a presença das palavras-chave escolhidas em comparação às palavras-chave dos artigos selecionados:

Quadro 2 - Verificação de Aderência das Palavras-chave

\begin{tabular}{|c|c|}
\hline Artigo & Palavras-chave \\
\hline $\begin{array}{l}\text { SKARE, M. HASIC, T. Corporate governance, firm performance, } \\
\text { and economic growth - theoretical analysis. Journal of Business } \\
\text { Economics and Management. Vilnius,v. 17, n. 1, p. 35-51. jan. } \\
2016 .\end{array}$ & $\begin{array}{l}\text { Capital } \\
\text { Corporate Governance } \\
\text { Economic Growth } \\
\text { Efficiency } \\
\text { Firm Performance } \\
\text { Gov Store } \\
\text { Stakeholders } \\
\text { Shareholders } \\
\text { Sustainability }\end{array}$ \\
\hline $\begin{array}{l}\text { MCCAULEY, D. Sustainability, Governance and Time: Exploring } \\
\text { 'Critical Junctures' in the Governance of Genetically Modified } \\
\text { Organisms in France. Environmental Policy and Governance. v. } \\
23, \text { n. 5, p. 283-296. set. } 2013\end{array}$ & $\begin{array}{l}\text { Civil Society } \\
\text { French Politics } \\
\text { GMOs } \\
\text { Governance } \\
\text { Historical Institucionalism } \\
\text { Sustanaible Development }\end{array}$ \\
\hline $\begin{array}{l}\text { FERRERO-FERRERO, I. FERNANDEZ-IZQUIERDO, M. A. MUÑOZ- } \\
\text { TORRES, M. J. Integrating Sustainability into Corporate } \\
\text { Governance: An Empirical Study on Board Diversity. Corporate } \\
\text { Social Responsibility and Environmental Management. } \\
\text { Sydney,v. 22, n. 4, p. 193-207. jul. } 2015\end{array}$ & $\begin{array}{l}\text { Board Diversity } \\
\text { Corporate Governance } \\
\text { Corporate Social Responsibility } \\
\text { Stakeholder } \\
\text { Sustanaible Development } \\
\text { Sustanaible Management }\end{array}$ \\
\hline
\end{tabular}

Fonte: Elaborado pelos autores (2017) 
Com a verificação da aderência das palavras-chave, constatou-se que não havia a necessidade de inclusão de novas palavras-chave, pois as selecionadas já estava alinhadas ao tema.

Após a verificção da aderência das palavras-chave, passou-se a efetuar o filtro do banco bruto de artigos, realizando-se primeiramente a exclusão dos artigos repetidos. Nesta etapa, utilizou-se o software Endnote $X 7$, excluindo 825 artigos duplicados, restando 1.943 artigos, dos quais foi efetuada a leitura do título, para verificação do alinhamento em relação ao tema. Nesta etapa, foram excluídos mais 1.858 artigos, restando 85 artigos não duplicados e alinhados ao tema pelo título.

Foi realizado posteriormente a verificação do reconhecimento científico desses 85 artigos, verificando a quantidade de citações desses com o auxílio do Google Scholar. Foi estabelecido como ponto de corte a quantidade mínima de 16 citações, sendo filtrados 39 artigos que correspondiam a 96,08\% das citações do Portfólio selecionado. Verificou-se também os artigos publicados nos últimos 2 anos (mesmo sem citações, totalizando 22 artigos) e se havia algum artigo com mais de 2 anos de publicação cujo autor possuía outro artigo com reconhecimento científico (mas nenhum artigo foi encontrado nestas condições) e incorporaramse estes aos 39 com reconhecimento científico, totalizando 61 artigos, dos quais foram lido os resumos para a verificação de alinhamento com o tema.

Após a leitura do resumo, foram excluídos 42, restando 19 artigos, dos quais foi verificada a disponibilidade do trabalho integral de forma gratuita (somente 1 artigo não estava disponível) e procedeuse a leitura integral dos mesmos, excluindo-se 4 artigos, restando 14 artigos não repetidos, com reconhecimento científico e alinhados após a leitura integral, que constituem o Portfólio Bibliográfico Primário (PBP) do estudo.

Como etapa final da seleção do Portfólio Bibliográfico, foi realizado o teste de representatividade, por meio da análise das referências dos 14 artigos do PBP. Foram identificadas 1033 referências, das quais 45 estavam alinhadas quanto ao título do artigo. Destas 28 foram selecionadas por possuírem reconhecimento científico (efetuado através da verificação da quantidade de citações com auxílio do Google Scholar), sendo estabelecido como ponto de corte a quantidade mínima de 100 citações (correspondendo a 98,49\% do total de citações). Desses 28 artigos, 11 estavam alinhados pela leitura do resumo, 2 já constam no PBP e 1 não estava disponível na íntegra. Após a leitura integral, 2 artigos foram incorporados ao PBP, totalizando 16 artigos que compuseram o Portfólio Final, conforme quadro 3:

Quadro 3 - Artigos do Portfólio Final

\begin{tabular}{|c|c|c|}
\hline Autores & Título do artigo & Ano \\
\hline $\begin{array}{l}\text { Beckmann, M., } \\
\text { Hielscher, S., Pies, I. }\end{array}$ & $\begin{array}{l}\text { Commitment Strategies for Sustainability: How Business Firms Can } \\
\text { Transform Trade-Offs Into Win-Win Outcomes }\end{array}$ & 2014 \\
\hline Ingley, C. B. & $\begin{array}{l}\text { Company growth and Board attitudes to corporate Social } \\
\text { Responsibility }\end{array}$ & 2008 \\
\hline $\begin{array}{l}\text { Chen, } \quad \text { C. H., } \\
\text { Wongsurawat, W. }\end{array}$ & Core constructs of corporate social responsibility: A path analysis & 2011 \\
\hline $\begin{array}{l}\text { Jamali, D., Safieddine, } \\
\text { A. M., Rabbath, M. }\end{array}$ & $\begin{array}{l}\text { Corporate Governance and Corporate Social Responsibility Synergies } \\
\text { and Interrelationships }\end{array}$ & 2008 \\
\hline $\begin{array}{l}\text { Ntim, } \quad \text { C. } \\
\text { Soobaroyen, } \mathrm{T} \text {. }\end{array}$ & $\begin{array}{l}\text { Corporate Governance and Performance in Socially Responsible } \\
\text { Corporations: New Empirical Insights from a Neo-Institutional } \\
\text { Framework }\end{array}$ & 2013 \\
\hline Gill, A. & Corporate Governance as Social Responsibility: A Research Agenda & 2008 \\
\hline $\begin{array}{l}\text { Tang, A. K. Y., Lai, K., } \\
\text { Cheng, T. C. E. }\end{array}$ & $\begin{array}{l}\text { Environmental Governance of Enterprises and their Economic } \\
\text { Upshot through Corporate Reputation and Customer Satisfaction }\end{array}$ & 2012 \\
\hline
\end{tabular}




\begin{tabular}{|c|c|c|}
\hline Aras, G., Crowther, D. & $\begin{array}{l}\text { Governance and sustainability - An investigation into the } \\
\text { relationship between corporate governance and corporate } \\
\text { sustainability }\end{array}$ & 2008 \\
\hline Espinosa, A. & Governance for sustainability: learning from VSM practice & 2015 \\
\hline $\begin{array}{l}\text { vanZeijl-Rozema, A., } \\
\text { Cörvers, R., Kemp, R., } \\
\text { Martens, P. }\end{array}$ & Governance for sustainable development: a framework & 2008 \\
\hline Sneirson, J. F. & $\begin{array}{l}\text { Green Is Good: Sustainability, Profitability, and a New Paradigm for } \\
\text { Corporate Governance }\end{array}$ & 2009 \\
\hline $\begin{array}{l}\text { Garvare, } \\
\text { Johansson, P. }\end{array}$ & Management for sustainability - a stakeholder theory & 2010 \\
\hline $\begin{array}{l}\text { Salvioni, D. M., } \\
\text { Gennari, F., Bosetti, L. }\end{array}$ & $\begin{array}{l}\text { Sustainability and convergence: The future of corporate governance } \\
\text { systems? }\end{array}$ & 2016 \\
\hline Johnson, M.P. & $\begin{array}{l}\text { Sustainability Management and Small and Medium-Sized } \\
\text { Enterprises: Managers' Awareness and Implementation of Innovative } \\
\text { Tools }\end{array}$ & 2015 \\
\hline Jo, H., Harjoto M. A. & $\begin{array}{l}\text { The Causal Effect of Corporate Governance on Corporate Social } \\
\text { Responsibility }\end{array}$ & 2012 \\
\hline $\begin{array}{l}\text { Klettner, A., Clarke, T., } \\
\text { Boersma, M. }\end{array}$ & $\begin{array}{l}\text { The Governance of Corporate Sustainability: Empirical Insights into } \\
\text { the Development, Leadership and Implementation of Responsible } \\
\text { Business Strategy }\end{array}$ & 2014 \\
\hline
\end{tabular}

Fonte: Elaborado pelos autores (2017)

\section{RESULTADOS}

Esta seção apresenta e analisa dos dados da pesquisa. São descritos e analisados os dados oriundos do portfólio bibliográfico construído.

\subsection{Análise bibliométrica: características básicas}

Após a seleção dos artigos para composição do portfólio final, foi realizada a análise bibliométrica dos mesmos, analisando os autores, periódicos e artigos de destaque do portfólio final e de suas referências.

Em relação aos autores do Portfólio Final, foram identificados 34 autores, todos com somente 1 publicação cada. Na análise dos periódicos, foram identificados 3 periódicos com 2 publicações cada: Business Strategy and the Enviroment, Corporate Governance- an International Reviewe Journal of Business Ethics. 0 quadro 4 demonstra a análise dos artigos do portfólio bibliográfico, conforme quantidade de citações:

Quadro 4 - Número de citações dos artigos do Portfólio Bibliográfico

\begin{tabular}{|l|l|l|}
\hline \multicolumn{1}{|c|}{ No } & \multicolumn{1}{|c|}{ Título do artigo } & $\begin{array}{l}\text { Número de } \\
\text { Citações }\end{array}$ \\
\hline 1 & $\begin{array}{l}\text { Corporate Governance and Corporate Social Responsibility Synergies and } \\
\text { Interrelationships }\end{array}$ & 368 \\
\hline 2 & The Causal Effect of Corporate Governance on corporate responsibility & 239 \\
\hline 3 & Governance and sustainability An Investigation into Relationship & 238 \\
\hline 4 & Corporate Governance as Social Responsibility A Research Agenda & 165 \\
\hline
\end{tabular}




\begin{tabular}{|l|l|l|}
\hline 5 & Management for sustainability - A stakeholder theory & 141 \\
\hline 6 & Governance for Sustainable Development A Framework & 134 \\
\hline 7 & $\begin{array}{l}\text { Green Is Good: Sustainability, Profitability, and a New Paradigm for Corporate } \\
\text { Governance }\end{array}$ & 115 \\
\hline
\end{tabular}

Fonte: Elaborado pelos autores (2017).

Verifica-se o destaque do artigo número Corporate Governance and Corporate Social Responsibility Synergies and Interrelationships, dos autores Jamali, Safieddine e Rabbath (2008), com 368 citações, bem como os artigos demais artigos do quadro 4,todos com mais de 100 citações cada.O número de citações desses artigos demonstra a relevância dos estudos selecionados, onde $43 \%$ dos artigos do Portfólio possuem mais de 100 citações. Além disso, somente três artigos do portfólio possuem menos de 20 citações.

Em relação às referências, foi efetuada a análise dos autores e periódicos com base nas referências brutas (todas as referências). Para análise dos artigos, foram utilizados os artigos das referências alinhados ao tema pelo título, que será detalhada a seguir.

Foram identificados 1484 autores, dos quais 894 possuíam apenas 1 publicação. O quadro 5 demonstra os autores de com o maior número de publicaçõesnas referências. Destacam-se os autores Hoje Jo, com 12 publicações e Ruth V. Aguilera, com 11 publicações:

Quadro 5 - Autores Referências

\begin{tabular}{|l|c|}
\hline \multicolumn{1}{|c|}{ Autor } & \multicolumn{1}{|c|}{$\begin{array}{c}\text { Número de } \\
\text { Publicações }\end{array}$} \\
\hline Jo, H. & 12 \\
\hline Aguilera, R.V. & 11 \\
\hline Clarke, T. & 9 \\
\hline Jensen, M. C. & 8 \\
\hline Jamali, D. & 8 \\
\hline Carroll, A.B. & 8 \\
\hline McWilliams, A. & 7 \\
\hline Harjoto, M. A. & 7 \\
\hline Siegel, D. & 6 \\
\hline Salvioni, D.M. & 6 \\
\hline Rupp, D. E. & 6 \\
\hline Espinosa, A. & 6 \\
\hline
\end{tabular}

Fonte: Elaborado pelos autores (2017).

Em relação aos periódicos, foram identificados 234, dos quais 143 possuem somente uma publicação nas referências. O quadro 6 demonstra os periódicos com o maior número de publicações nas referências. Destaca-se o periódico Journal of Business Ethics, com 73 publicações.

Quadro 6 - Periódicos Referências

\begin{tabular}{|l|c|}
\hline \multicolumn{1}{|c|}{ Periódico } & $\begin{array}{c}\text { Número de } \\
\text { Publicações }\end{array}$ \\
\hline Journalof Business Ethics & 73 \\
\hline Corporate Governance:An International Review & 42 \\
\hline Business StrategyandtheEnvironment & 35 \\
\hline Academyof Management Review, & 25 \\
\hline Corporate Social Responsibilityand Environmental Management & 24 \\
\hline StrategicManagement Journal & 21 \\
\hline
\end{tabular}

Fonte: Elaborado pelos autores (2017). 
O quadro 7 demonstra os artigos das referências com maior número de citações, destacando-se os dois primeiros artigos, com mais de 10 mil citações (consulta efetuada através do google scholar):

Quadro 7 -Número de citações dos artigos das Referências do Portfólio Bibliográfico

\begin{tabular}{|l|c|}
\hline \multicolumn{1}{|c|}{ Título do Artigo } & $\begin{array}{c}\text { Número de } \\
\text { Citações }\end{array}$ \\
\hline The Social responsibility of business is to increase its profits' & 13798 \\
\hline $\begin{array}{l}\text { The stakeholder theory of the corporation: concepts, evidence, and } \\
\text { implications }\end{array}$ & 10245 \\
\hline $\begin{array}{l}\text { The pyramid of corporate social responsibility: Toward the moral } \\
\text { management of organizational stakeholders }\end{array}$ & 7136 \\
\hline Corporate social responsibility: a theory of the firm perspective & 4855 \\
\hline Beyond the business case for corporate sustainability & 2297 \\
\hline Corporate social responsibility: Strategic implications & 2243 \\
\hline $\begin{array}{l}\text { Towards the sustainable corporation: win-win-win business strategies for } \\
\text { sustainable development }\end{array}$ & 1937 \\
\hline
\end{tabular}

Fonte: Elaborado pelos autores (2017).

Após efetuar a análise individualizada de cada variável (autores, periódicos e artigos) no Portfólio e nas Referências, foi efetuado o cruzamento das informações, para verificação dos autores e periódicos com maior quantidade de publicações tanto nas referências quanto no portfólioPortfólio.

Foram identificados 21 autores com publicações no portfólio e referências. O gráfico 1 demonstra os autores com maior número de publicações.

Gráfico 1 - Autores de destaque no Portfólio Bibliográfico e Referências

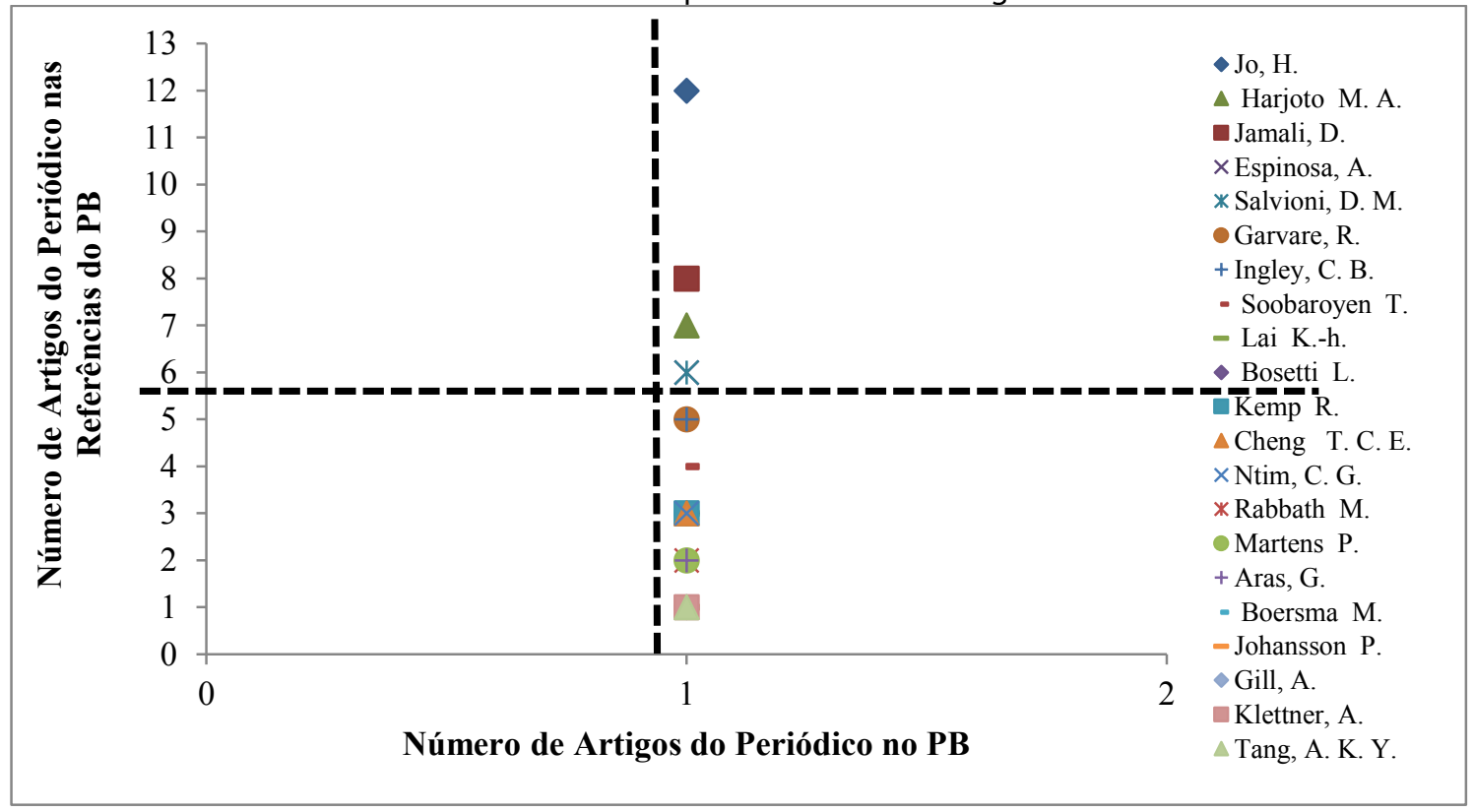

Fonte: Elaborado pelos autores (2017).

Conforme demonstrado no início desta seção, nenhum autor possui mais de 1 publicação no Portfólio Bibliográfico. Destaca-se o autor Hoje Jo, com 12 publicações nas referências. O autor atua como professor de Finanças da Santa Clara University (Estados Unidos), possui publicações nas áreas de Governança Corporativa e Responsabilidade Social Corporativa, com 4426 citações conforme Google Scholar.

Em relação aos periódicos, foram identificados 10 com publicações no Portfólio Bibliográfico e referências. $O$ gráfico 2 demonstra a quantidade de publicações de cada um deles. 
Gráfico 2 - Periódicos do Portfólio Bibliográfico e Referências

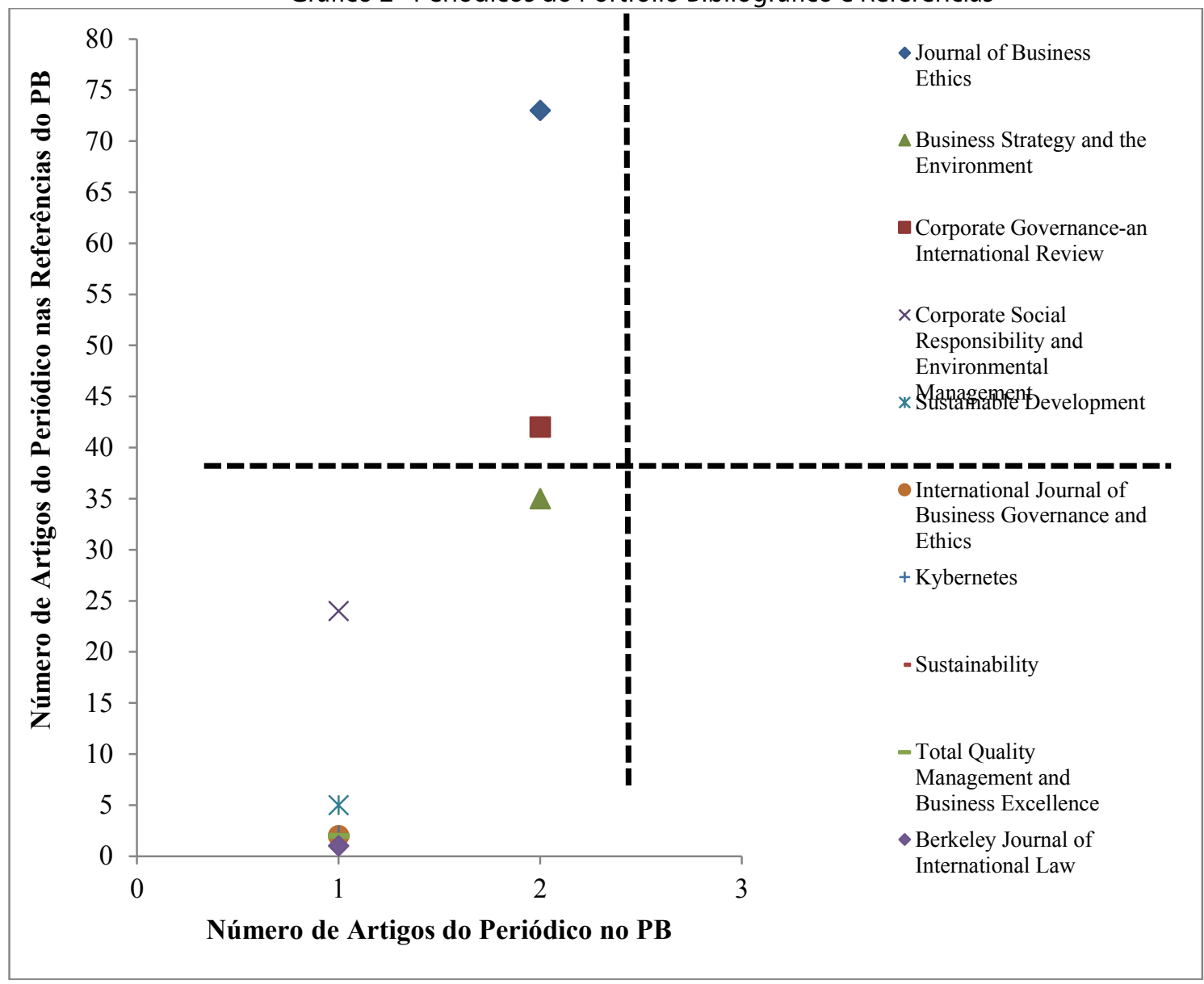

Fonte: Elaborado pelos autores (2017).

Podem-se destacar três periódicos, com duas publicações no Portfólio Bibliográfico e mais de 30 publicações nas referências: Journal of Business Ethics, Business Strategy and the Environment Corporate Governance- an International Review. Desses, pode-se ressaltar o Journal of Business Ethics, com 73 publicações nas referências e duas no Portfólio Bibliográfico. Este periódico publica artigos originais com uma ampla variedade de perspectivas metodológicas e disciplinares sobre questões éticas relacionadas aos negócios.

\subsection{Análise bibliométrica: características avançadas}

Para elaboração das variáveis avançadas, foram utilizados os quatro princípios do Capitalismo Consciente, conforme Mackey e Sisodia (2014): (1) propósito maior: razão de existência da empresa, que vai além de gerar lucro e criar valor para os investidores; (2) Integração de stakeholders (todas as entidades que impactam ou são impactadas pela organização): todos estão conectados e são interdependentes e o negócio deve otimizar a criação de valor para eles; (3) Liderança Consciente: líderes que busca soluções sinérgicas, rejeitando a visão de negócios orientadas para trade-offs, agregando valor para os stakeholders e agindo de acordo com o propósito maior da organização; e (4) Cultura e Gestão Conscientes: cultura que garante estabilidade à organização, assegurando que os valores e propósito sobreviverão ao longo do tempo e às mudanças de liderança. Compartilham de características como confiança, responsabilidade, transparência, integridade, lealdade, igualitarismo, justiça e crescimento pessoal. A gestão consciente utiliza uma abordagem compatível com esta cultura.

O quadro 8 demonstra as perguntas elaboradas para comparação com os artigos do Portfólio Bibliográfico e os resultados apurados desta análise: 
Quadro 8 - Análise das Variáveis Avançadas

\begin{tabular}{|c|c|c|c|c|}
\hline \multicolumn{5}{|c|}{ Princípios do Capitalismo Consciente } \\
\hline Número/Artigo & $\begin{array}{l}\text { Propósito Maior: há a } \\
\text { citação da necessidade de } \\
\text { existência de um } \\
\text { propósito maior para a } \\
\text { organização? }\end{array}$ & $\begin{array}{c}\text { Gestão de Stakeholders: } \\
\text { Quais Stakeholders são } \\
\text { citados e como é relatada } \\
\text { a relação das } \\
\text { organizações com estes? }\end{array}$ & $\begin{array}{l}\text { Liderança Consciente: } \\
\text { Qual é o papel, } \\
\text { importância ou função dos } \\
\text { líderes na organização? } \\
\text { Como é citado no artigo? }\end{array}$ & $\begin{array}{l}\text { Cultura e Gestão Conscientes: São } \\
\text { mencionados valores ou } \\
\text { princípios a serem seguidos pela } \\
\text { Governança Corporativa? Quais as } \\
\text { influências existem sobre a } \\
\text { Governança Corporativa? }\end{array}$ \\
\hline $\begin{array}{l}\text { 1- BECKMANN, M., HIELSCHER, S., } \\
\text { PIES, I. Commitment Strategies for } \\
\text { Sustainability: How Business Firms } \\
\text { Can Transform Trade-Offs Into Win- } \\
\text { Win Outcomes. Business Strategy } \\
\text { and the Environment. } 2014\end{array}$ & Não Citado & $\begin{array}{l}\text { Os trade-offs podem ser } \\
\text { superados por reformas } \\
\text { institucionais, criando assim } \\
\text { um potencial vantajoso } \\
\text { para ganhos mútuos. }\end{array}$ & Não citado & Não Citado \\
\hline $\begin{array}{l}\text { 2- INGLEY, C. B. Company growth } \\
\text { and Board attitudes to corporate } \\
\text { Social Responsibility. International } \\
\text { Journal of Business Governance and } \\
\text { Ethics. } 2008\end{array}$ & Não Citado & \begin{tabular}{|l|} 
Relacionamento com \\
investidores mais valorizado \\
do que demais stakeholders.
\end{tabular} & $\begin{array}{l}\text { Tarefas mais importantes dos } \\
\text { diretores: envolvimento com } \\
\text { a estratégia, resultados, } \\
\text { determinação da exposição } \\
\text { ao risco e responsabilidade } \\
\text { por condutas éticas. }\end{array}$ & Não Citado \\
\hline $\begin{array}{l}\text { 3- CHEN, C. H., WONGSURAWAT, } \\
\text { W.Core constructs of corporate social } \\
\text { responsibility: A path analysis. Asia- } \\
\text { Pacific Journal of Business } \\
\text { Administration2011. }\end{array}$ & Não Citado & Não Citado & Não citado & $\begin{array}{l}\text { A transparência pode reforçar a } \\
\text { competitividade, o que por sua vez } \\
\text { irá influenciar positivamente o seu } \\
\text { compromisso de ser mais } \\
\text { socialmente responsável. }\end{array}$ \\
\hline $\begin{array}{l}\text { 4- JAMALI, D., SAFIEDDINE, A. M., } \\
\text { RABBATH, M.Corporate Governance } \\
\text { and Corporate Social Responsibility } \\
\text { Synergies and Interrelationships. } \\
\text { Corporate Governance-an } \\
\text { International Review } 2008 \text {. }\end{array}$ & Não Citado & Não Citado & Não Citado & $\begin{array}{l}\text { Quanto mais robusta for a estrutura } \\
\text { da Governança Corporativa, mais } \\
\text { provável será a condução ou } \\
\text { direcionamento para a RSE }\end{array}$ \\
\hline
\end{tabular}


5- NTIM, C. G., SOOBAROYEN, T.Corporate Governance and Performance in Socially Responsible Corporations: New Empirical Insights Não Citado from a Neo-Institutional Framework. Corporate Governance-an International Review2013.

\begin{tabular}{|c|c|c|c|}
\hline Não Citado & $\begin{array}{l}\text { Os esforços para aprimorar } \\
\text { as práticas de diretoria, } \\
\text { transparência contábil e } \\
\text { divulgação para os } \\
\text { acionistas devem ser } \\
\text { buscados junto com } \\
\text { tentativas de abordar as } \\
\text { preocupações das partes } \\
\text { interessadas, tais como } \\
\text { funcionários, clientes e } \\
\text { comunidades sobre meio } \\
\text { ambiente, ética, saúde e } \\
\text { segurança, entre outros. }\end{array}$ & Não citado & $\begin{array}{l}\text { Uma combinação de } \\
\text { Responsabilidade Social Corporativa } \\
\text { e Governança Corporativa tem um } \\
\text { forte efeito positivo na Performance } \\
\text { Financeira, o que significa que a } \\
\text { Governança Corporativa modera } \\
\text { positivamente a conexão } \\
\text { Responsabilidade Social Corporativa } \\
\text { e Performance Financeira. }\end{array}$ \\
\hline Não Citado & Não Citado & Não citado & $\begin{array}{l}\text { O estudo da governança corporativa } \\
\text { está gradualmente incorporando } \\
\text { conceitos como índices não } \\
\text { financeiros, códigos de ética e } \\
\text { padrões de conduta, investimento } \\
\text { social e deveres fiduciários, } \\
\text { diversidade de diretoria, } \\
\text { engajamento de stakeholders, } \\
\text { relatórios de sustentabilidade } \\
\text { estratégias de negócios socialmente } \\
\text { responsáveis. }\end{array}$ \\
\hline Não Citado & Não Citado & Não citado & $\begin{array}{l}\text { A governança ambiental promove a } \\
\text { reputação verde, o que contribui } \\
\text { favoravelmente para a reputação } \\
\text { geral da empresa } \\
\text { subsequentemente para } \\
\text { desempenho econômico. }\end{array}$ \\
\hline
\end{tabular}




\begin{tabular}{|c|c|c|c|c|}
\hline $\begin{array}{l}\text { 8- ARAS, G., CROWTHER, } \\
\text { D.Governance and sustainability-An } \\
\text { investigation into the relationship } \\
\text { between corporate governance and } \\
\text { corporate sustainability. } \\
\text { Management Decision. } 2008 \text {. }\end{array}$ & Não Citado & Não Citado & Não citado & $\begin{array}{l}\text { Uma empresa que tenha uma } \\
\text { compreensão mais completa da } \\
\text { sustentabilidade e da governança } \\
\text { corporativa abordará essas questões } \\
\text { de forma mais plena. }\end{array}$ \\
\hline $\begin{array}{l}\text { 9- ESPINOSA, A. Governance for } \\
\text { sustainability: learning from VSM } \\
\text { practice. } \\
\text { Kybernetes } 2015 \text {. }\end{array}$ & Não Citado & Não Citado & Não citado & Não Citado \\
\hline $\begin{array}{l}\text { 10-VAN ZEIJL-ROZEMA, A., CÖRVERS, } \\
\text { R., KEMP, R., MARTENS, P.Governance } \\
\text { for sustainable development: a } \\
\text { framework. } \\
\text { Sustainable Development2008. }\end{array}$ & Não Citado & Não Citado & Não citado & $\begin{array}{l}\text { O desenvolvimento sustentável não } \\
\text { pode ser alcançado sem a } \\
\text { governança por sua natureza: } \\
\text { promover objetivos comuns por } \\
\text { meio da ação coletiva }\end{array}$ \\
\hline $\begin{array}{l}\text { 11- SNEIRSON, J. F.Green Is Good: } \\
\text { Sustainability, Profitability, and a } \\
\text { New Paradigm for Corporate } \\
\text { Governance. } \\
\text { lowa Law Review2009. }\end{array}$ & Não Citado & Não Citado & Não citado & $\begin{array}{l}\text { As corporações não devem mais ver } \\
\text { o direito corporativo, as normas e as } \\
\text { pressões do mercado como } \\
\text { obstáculos ao negócio sustentável. }\end{array}$ \\
\hline $\begin{array}{l}\text { 12- GARVARE, R., JOHANSSON, } \\
\text { P.Management for sustainability - a } \\
\text { stakeholder theory. } \\
\text { Total Quality Management and } \\
\text { Business Excellence2010. }\end{array}$ & Não Citado & $\begin{array}{l}\text { A sustentabilidade } \\
\text { organizacional será } \\
\text { alcançada se a organização } \\
\text { conseguir satisfazer ou } \\
\text { exceder infinitamente as } \\
\text { demandas de seus } \\
\text { stakeholders. }\end{array}$ & Não citado & Não Citado \\
\hline $\begin{array}{l}\text { 13- SALVIONI, D. M., GENNARI, F., } \\
\text { BOSETTI, L.Sustainability and } \\
\text { convergence: The future of corporate } \\
\text { governance systems? } \\
\text { Sustainability.2016, }\end{array}$ & Não Citado & Não Citado & $\begin{array}{|lr|}\text { A diretoria tem um papel } & \text { na } \\
\text { fundamental } & \text { da } \\
\text { incorporação } & \text { sustentabilidade na cultura } \\
\text { empresarial, com efeitos nas }\end{array}$ & Não Citado \\
\hline
\end{tabular}




\begin{tabular}{|c|c|c|c|c|}
\hline & & & $\begin{array}{l}\text { estratégias da empresa e no } \\
\text { comportamento dos } \\
\text { funcionários. }\end{array}$ & \\
\hline $\begin{array}{l}\text { 14- JOHNSON, M. P.Sustainability } \\
\text { Management and Small and } \\
\text { Medium-Sized } \\
\text { Managers' Anterprises: } \\
\text { Implementation of Innovative Tools. } \\
\text { Corporate Social Responsibility and } \\
\text { Environmental Management2015. }\end{array}$ & Não Citado & Não Citado & $\begin{array}{lr}\text { Os gestores informados } \\
\text { (sobre ferramentas de } \\
\text { implementação } & \text { da } \\
\text { sustentabilidade) } & \text { são } \\
\text { capazes de tomar decisões } \\
\text { que afetam positivamente o } \\
\text { desenvolvimento } & \text { do } \\
\text { programa } & \text { de } \\
\text { sustentabilidade. }\end{array}$ & Não Citado \\
\hline $\begin{array}{l}\text { 15- JO, H., HARJOTO M. A. The Causal } \\
\text { Effect of Corporate Governance on } \\
\text { Corporate Social Responsibility. } \\
\text { Journalof Business Ethics } 2012 \text {. }\end{array}$ & Não Citado & $\begin{array}{l}0 \text { envolvimento das } \\
\text { empresas } r \text { em } \\
\text { Responsabilidade Social na } \\
\text { comunidade, no meio } \\
\text { ambiente, na diversidade e } \\
\text { no funcionário melhora } \\
\text { positivamenter a } \\
\text { Performance Financeira. }\end{array}$ & Não citado & Não Citado \\
\hline $\begin{array}{l}\text { 16- KLETTNER, A., CLARKE, T., } \\
\text { BOERSMA, M. The Governance of } \\
\text { Corporate Sustainability: Empirical } \\
\text { Insights into the Development, } \\
\text { Leadership and Implementation of } \\
\text { Responsible Business Strategy. } \\
\text { Journal of Business Ethics } 2014 \text {. }\end{array}$ & Não Citado & Não Citado & $\begin{array}{l}\text { Encontramos evidências de } \\
\text { estruturas de liderança } \\
\text { sendo implementadas para } \\
\text { garantir que a diretoria e a } \\
\text { alta administração estejam } \\
\text { envolvidas ro } \\
\text { desenvolvimento } \\
\text { estratégia } \\
\text { sustentabilidade. }\end{array}$ & $\begin{array}{l}\text { A governança sustentável deve estar } \\
\text { no mais alto nível da corporação e } \\
\text { não somente no departamento de } \\
\text { marketing e comunicações. }\end{array}$ \\
\hline
\end{tabular}

Fonte: Elaborado pelos autores (2017). 
Após análise das variáveis avançadas, verificou-se que nenhum dos artigos do portfólio Bibliográfico discorre especificamente sobre a teoria do Capitalismo Consciente. No entanto, pode-se verificar que, conforme disposto no quadro 8, somente 1 artigo (Governance for Sustainability: Learningv from VSM Practice) não cita nenhum dos quatro princípios do Capitalismo Consciente.

Outro fato observado foi o de nenhum dos artigos apresentarem o princípio do Propósito Maior, tido como "o ponto de partida para um negócio consciente: reconhecer o que faz com que a empresa seja verdadeiramente única e descobrir a melhor maneira de como ela pode servir ao mundo [...]" (MACKEY; SISODIA, 2014, p. 46). Esta constatação corrobora com o fato de nenhum dos artigos do Portfólio Bibliográfico tratarem especificamente da teoria do Capitalismo Consciente.

Em relação aos demais princípios, verifica-se que cinco artigos $(31,25 \%)$ discorrem sobre o Gestão de Stakeholders, quatro (25\%) sobre Liderança Consciente e nove $(56,25 \%)$ sobre Cultura e Gestão Conscientes. A seguir, será apresentada a análise dos conteúdos dos artigos em relação a cada um dos princípios.

Sobre o princípio de Gestão de Stakeholders, conforme os artigos 1, 5, 12 e 15, constata-se que: (i) os trade-offs podem ser superados por reformas institucionais (gerando um potencial para ganhos mútuos); (ii) as práticas da Governança Corporativa (diretoria, transparência e divulgação para acionistas) devem ser buscados em conjunto com os interesses dos demais stakeholders; (iii) a sustentabilidade organizacional será alcançada se a organização satisfazer ou exceder as demandas dos stakeholders; e (iv) o envolvimento da empresa com a comunidade, meio ambiente e funcionários (que são alguns dos stakeholders da empresa) melhora positivamente a performance financeira. Estas quatro afirmações em relação a Gestão de Stakeholders corroboram com a teoria do Capitalismo Consciente, que afirma cada um dos stakeholders é importante, todos estão conectados e são interdependentes e que o negócio deve buscar otimizar valores para esta rede. Além disso, devem-se procurar as sinergias entre as partes interessadas, evitando trade-offs (MACKEY; SISODIA, 2014). Por outro lado, os resultados empíricos do artigo 2 demonstram que os gestores participantes da pesquisa valorizam mais o relacionamento com os investidores do que com os demais stakeholders, divergindo do princípio de Gestão de stakeholders da teoria do Capitalismo Consciente conforme acima.

Em relação ao princípio da Liderança Consciente, conforme os artigos 13, 14 e 16, constata-se: (i) a diretoria tem papel fundamental na incorporação da sustentabilidade na cultura empresarial; (ii) gestores informados (sobre ferramentas de implementação da sustentabilidade) são capazes de tomar decisões que afetam positivamente o desenvolvimento de programas de sustentabilidade; e (iii) há evidências de implementação de estruturas de liderança (ou normas corporativas) para que a diretoria e alta administração estejam envolvidas no desenvolvimento de estratégias de sustentabilidade. Podese verificar que estas afirmações (de envolver as lideranças/diretoria com estratégias e gestão sustentáveis) corroboram com a teoria do Capitalismo Consciente, que afirma que sem liderança não é possível realizar negócios conscientes, pois são os líderes que disseminam a cultura e gestão de forma consciente (MACKEY; SISODIA, 2014). A preocupação com o desenvolvimento sustentável (que é um dos objetivos do Capitalismo Consciente) deve estar presente nas lideranças, para que estas possam direcionar os demais funcionários e stakeholder sem relação este objetivo. Por outro lado, os resultados empíricos do artigo 2 demonstram que os gestores participantes da pesquisa consideram que 0 envolvimento na estratégia, resultados financeiros e determinação da exposição ao risco são as tarefas mais importantes para os gestores, divergindo do princípio da Liderança Consciente, conforme detalhado acima.

Por fim, em relação ao princípio da Cultura e Gestão Conscientes, verifica-se que conforme os artigos 4, 5, 6, 7, 8, 10, 11 e 16, a Governança Corporativa deve ser associada à Responsabilidade Social Corporativa, devendo esta ser objeto de atenção da organização, e que a Governança com princípios sustentáveis influencia positivamente a imagem e os resultados da organização. Além disso, verifica-se a necessidade de a organização gerir adequadamente esta questão (devendo compreender melhor esta questão para abordá-la de forma mais plena), uma vez que o desenvolvimento sustentável não pode ser alcançado sem a Governança e que o estudo da Governança Corporativa está cada vez mais 
incorporando índices não financeiros. Tais afirmações corroboram com o princípio da Cultura e Gestão Conscientes, onde estas (cultura e gestão/governança) devem estar em convergência com o propósito da empresa e desenvolvimento sustentável, conferindo força e estabilidade à organização e seus valores centrais, como confiança, responsabilidade, transparência e integridade (MACKEY; SISODIA, 2014). Outra afirmação que corrobora com este princípio é do artigo 3 , onde verifica-se que a transparência pode reforçar a competitividade e o compromisso de ser mais socialmente responsável.

Após a análise individual de cada princípio, verifica-se que a maior parte dos artigos (quatorze, que correspondem a $87,50 \%$ do Portfólio Bibliográfico) possuem convergências com a Teoria do Capitalismo consciente, contra somente um artigo (que corresponde a 6,25\% do Portfólio Bibliográfico) que possui divergências. Desta forma, pode-se concluir que, apesar de nenhum dos artigos tratarem especificamente da teoria do Capitalismo Consciente, que há muitas convergências entre esta teoria e os resultados dos artigos do Portfólio Bibliográfico, demonstrando que esta teoria pode ser uma opção para a questão de como incorporar valores e diretrizes sustentáveis na Governança Corporativa e criar valor a longo prazo.

\section{CONSIDERAÇÕES FINAIS}

Este trabalho teve por objetivo analisar as características básicas e avançadas das publicações internacionais relacionadas ao recorte do tema Capitalismo Consciente e Governança Corporativa, por meio do instrumento KnowledgeDevelopmentProcess - Constructivist (ProKnow-C). Esse objetivo foi alcançado, efetuado por meio da seleção do portfólio bibliográfico pelo instrumento ProKnow- $C$, resultando em um portfólio de 16 artigos.

Por meio da análise bibliométrica, verificou-se que o autor de destaque foi Hoje Jo, que possui publicações principalmente nas áreas de Governança Corporativa e Responsabilidade Social Corporativa (áreas abordadas neste trabalho). O periódico de destaque foi o Journal of Business Ethics, que publica artigos com uma ampla variedade de perspectivas metodológicas e disciplinares sobre questões éticas relacionadas aos negócios.

Através da análise das variáveis avançadas, observou-se que nenhum dos artigos do portfólio bibliográfico trata especificamente da teoria do Capitalismo Consciente e que nenhum dos artigos mencionou a necessidade de a organização possuir um propósito maior (primeiro princípio do Capitalismo Consciente). Por outro lado, verificou-se que a maioria dos artigos do portfólio (87,50\%) possui convergências com a teoria, no que se refere à gestão de stakeholders, liderança consciente $\mathrm{e}$ cultura e gestão conscientes. Esta constatação demonstra que a teoria do Capitalismo Consciente pode ser um meio para as organizações se desenvolverem de forma sustentável (sem prejuízo para as gerações futuras), conciliando os interesses dela e da sociedade de uma forma geral.

O fato de não ter sido localizado nenhum artigo na seleção do Portfólio Bibliográfico que trate especificamente desta teoria pode ser explicado pela ausência de resumo e palavras-chave de artigos de alguns periódicos (como a California Management Review), o que limitaria a busca de palavras chave somente ao título do artigo. Além disso, durante a busca de um artigo para a construção das variáveis avançadas deste trabalho (além da realizada através do ProKnow-C) também revelou que a teoria do Capitalismo Consciente ainda é pouco explorada, no que se refere a publicações internacionais.

Como limitações desta pesquisa, pode-se citar a ausência de artigos que tratam da teoria do Capitalismo Consciente, a restrição da pesquisa a artigos escritos em língua inglesa publicados em revistas indexadas às bases de dados constantes no portal de periódicos da CAPES e a construção e análise das variáveis avançadas ter sido efetuada conforme a interpretação dos autores.

Por fim, sugere-se para trabalhos futuros a realização da pesquisa somente pelo termo Conscious Capitalism nas bases de dados (uma vez que a teoria possui poucas publicações) visando efetuar uma análise (bibliométrica e de conteúdo) de artigos que tratem especificamente sobre a teoria do Capitalismo Consciente e a realização de pesquisas empíricas (estudos de caso por exemplo) em organizações que estão implantando ou já implantaram os princípios do Capitalismo Consciente. 


\section{REFERÊNCIAS}

ARAS, G.; CROWTHER, D. Governance and sustainability - An investigation into the relationship between corporate governance and corporate sustainability. Management Decision, v. 46, n. 3, p. 433-448. 2008

BECKMANN, M.; HIELSCHER, S.; PIES, I. Commitment Strategies for Sustainability: How Business Firms Can Transform Trade-Offs Into Win-Win Outcomes. Business Strategy and the Environment, n. 23, p. 18-37. 2014

CHEN, C. H.; WONGSURAWAT, W. Core constructs of corporate social responsibility: A path analysis. Asia-Pacific Journal of Business Administration, v. 3 n. 1, p. 47-61. 2011

COOPER; D. R.; SCHINDLER, P.S. Método de pesquisa em Administração. 7. ed. Porto Alegre: Bookmann, 2011.

ENSSLIN, L. et al. ProKnow-C, Knowledge Development Process - Constructivist: processo técnico com patente de registro pendente junto ao INPI. Brasil: [s.n.], 2010.

ESPINOSA, A. Governance for sustainability: learning from VSM practice. Kybernetes, v. 44, n. 6/7 p. 955-969, 2015.

GARVARE, R.; JOHANSSON, P. Management for sustainability - a stakeholder theory. Total Quality Management and Business Excellence, v. 21, n. 7, p. 737-744, 2010.

GILL, A. Corporate Governance as Social Responsibility: A Research Agenda. Berkeley Journal of International Law, v. 26, n. 2, p. 452-478, 2008.

INGLEY, C. B. Company growth and Board attitudes to corporate Social. Responsibility. International Journal of Business Governance and Ethics, v. 4, n. 1, p. 17-39, 2008.

JAMALI, D.; SAFIEDDINE, A. M.; RABBATH, M. Corporate Governance and Corporate Social Responsibility Synergies and Interrelationships. Corporate Governance-an International Review, v. 16, n. 5, p. 443-459, 2008.

JO, H.; HARJOTO, M. A. The Causal Effect of Corporate Governance on Corporate Social Responsibility. Journal of Business Ethics, v. 106, p. 53-72, 2012.

JOHNSON, M. P. Sustainability Management and Small and Medium-Sized Enterprises: Managers' Awareness and Implementation of Innovative Tools. Corporate Social Responsibility and Environmental Management, v. 22, p. 271-285, 2015.

KLETTNER, A.; CLARKE, T.; BOERSMA, M. The Governance of Corporate Sustainability: Empirical Insights into the Development, Leadership and Implementation of Responsible Business Strategy. Journal of Business Ethics, v. 122, n. 1, p. 145-165, 2014.

MACHADO, D. P.; OTT, E. Estratégias de Legitimação Social Empregadas na Evidenciação Ambiental: Um Estudo à Luz da Teoria da Legitimidade. Revista Universo Contábil, v. 11, n. 1, p. 136-156, 2015.

MACKEY, J.; SISODIA R. Capitalismo Consciente: Como Libertar o Espirito Heroico dos Negócios. São Paulo: HSM Editora, 2014.

MARTIN, K. D.; JOHNSON, J. L.; FRENCH, J. J. Institutional pressures and marketing ethics initiatives: the focal role of organizational identity. Journal of the Academy of Marketing Science, v. 39, n. 4, p. 574591, 2011. 
NTIM, C. G.; SOOBAROYEN, T. Corporate Governance and Performance in Socially Responsible Corporations: New Empirical Insights from a Neo-Institutional Framework. Corporate Governance-an International Review, v. 21, n. 5, p. 468-494, 2013.

RICHARDSON, R. J.; PERES, J. A. de S. Pesquisa social: métodos e técnicas. 3. ed. São Paulo, SP: Atlas, 2012. 334p.

SALVIONI, D. M.; GENNARI, F.; BOSETTI, L. Sustainability and convergence: The future of corporate governance systems? Sustainability, v. 8, n. 11, p. 1-25, 2016.

SNEIRSON, J. F. Green Is Good: Sustainability, Profitability, and a New Paradigm for Corporate Governance. lowa Law Review, v. 4, n. 22, p. 987-1022, 2009.

TANG, A. K. Y.; LAI, K.; CHENG, T. C. E. Environmental Governance of Enterprises and their Economic Upshot through Corporate Reputation and Customer Satisfaction. Business Strategy and the Environment, v. 21, p. 401-411, 2012.

VALMORBIDA, S. M. I.; ENSSLIN, S. R. Avaliação de Desempenho de Rankings Universitários: Revisão da Literatura e diretrizes para futuras investigações. In: ENCONTRO NACIONAL DA ANPAD (EnANPAD), 29., 2015, Belo Horizonte. Anais do XXXIX Encontro da ANPAD (EnANPAD 2015). Belo Horizonte, MG: ANPAD, 2015.

VAN ZEIJL-ROZEMA, A.; CÖRVERS, R.; KEMP, R.; MARTENS, P. Governance for sustainable development: a framework. Sustainable Development, v. 16, p. 410-421, 2008.

WEI, Y. C.; EGRI, C. P.; LIN, C. Y. Y. Do corporate social responsibility practices yield different business benefits in eastern and western contexts? Chinese Management Studies, v. 8, n. 4, p. 556-576, 2014. 